Cómo citar este artículo / How to cite this article: Marmolejo Cantos, F. (2021). Un conjunto de cuevas acantiladas con alquería: el despoblado andalusí de Algaraceite (Casarabonela - Málaga). Lucentum, XL, 329-343. https://doi.org/10.14198/LVCENTVM.18506

\title{
UN CONJUNTO DE CUEVAS ACANTILADAS CON ALQUERÍA: EL DESPOBLADO ANDALUSÍ DE ALGARACEITE (CASARABONELA - MÁLAGA)
}

\author{
A HANGING CAVES-GROUP WITH VILLAGE. THE CASE OF THE MEDIEVAL ABANDONED VILLAGE \\ OF ALGARACEITE (CASARABONELA - MALAGA)
}

Recepción: 26/12/2020

Aceptación: 07/06/2021

\section{Resumen}

Se plantea el estudio de un grupo de cuevas acantiladas situadas en el occidente malagueño, con un horizonte cronológico que abarca desde el periodo altomedieval hasta el pasado siglo XX. Sus características formales hacen posible su adscripción con las cuevas-refugio inventariadas por M. Bertrand en el Sudeste de al-Andalus; aunque nada impide apreciar otros usos alternativos o complementarios en diferentes etapas históricas. Del estudio que presentamos, cabe introducir como hipótesis que los complejos de cuevas-vivienda acantiladas, con varios niveles superpuestos, podrían ser una clara evolución tipológica de estas cuevas-refugio de carácter defensivo.

Palabras claves. Cuevas acantiladas; cuevas-refugio; trogloditismo; arqueología espacial.
FRANCISCO MARMOLEJO CANTOS

Estudios del Occidente Malagueño

arqueologiacoin@gmail.com

https://orcid.org/0000-0002-5124-9426

\begin{abstract}
We present a group of cliff dwellings, located in the western area of the Malaga region (Spain), interconnected by narrow passageways, whose chronological horizon can be established in the Andalusian period. The formal characteristics allow their identification with the refuge caves documented by M. Bertrand in the southeast of al-Andalus, although other alternative or complementary uses in different historical periods can be also appreciated. This study introduces the hypothesis that the cliff-dwellings with several overlapping levels could be a clear typological evolution of these defensive refuge caves.
\end{abstract}

Key words. Group of cliff dwellings; refuge caves; troglodytism; landscape archeology. 


\section{CONSIDERACIONES PRELIMINARES}

Algaraceite es un despoblado andalusí situado en los confines de los términos de Casarabonela y Ardales, bajo los tajos escarpados de la sierra de Alcaparaín, al noroeste de la capital malagueña (Fig. 1) ${ }^{1}$. Nos hallamos ante un sistema de hábitat complejo, definido por viviendas convencionales y espacios subterráneos, que bien puede responder al modelo de asentamiento de origen tribal árabe o beréber. Se trataría por tanto de un hábitat troglodítico de carácter defensivo que convive con otras formas de asentamiento dentro del mismo enclave.

La superficie arqueológica se puede dividir en tres sectores en función de su uso. La parte central acoge el grupo principal de cuevas acantiladas, donde vamos a centrar nuestro estudio. A sus pies se extiende el espacio de hábitat, albergando restos de estructuras domésticas levantadas en mampostería, algunas aprovechando abrigos naturales dispuestos a nivel de suelo. En último término, se desarrolló un pequeño espacio irrigado adyacente al caserío, generado a partir de un venero, que se extendió posteriormente a las terrazas fluviales del río Turón.

En una visión de conjunto, las cuevas acantiladas en estudio se encuentran unidas por estrechos pasadizos laterales en su interior. Se disponen alineadas en el punto más alto y mejor defendible del asentamiento, pasando desapercibidas en el paisaje, ocultas a la vista y plenamente integradas en la naturaleza. Reúnen excelentes condiciones de habitabilidad, con techos de suficiente altura, buena luz y ventilación, al tiempo que dominan visualmente el tránsito de personas y mercancías por el puerto de la Ferradura, vía natural que conectaba la cuenca fluvial del Turón con las tierras de Ortegícar y Cañete (Fig. 1).

Se inscriben tipológicamente dentro de las denominadas cuevas acantiladas, con las especificidades que examinaremos. Las diferencias y analogías observadas con respecto a las series elaboradas por Bertrand (1990) nos hacen ser cautos en lo tocante a su atribución funcional, aun teniendo signos inequívocos de ocupación humana en época alto y bajomedieval. En las páginas que siguen, analizaremos las diversas propuestas de interpretación que mejor se adecuan a la realidad arqueológica del enclave, insertándolo dentro de un marco de análisis más amplio.

Del estudio documental y arqueológico llevado a cabo sobre el conjunto principal, destacamos su interpretación como cuevas-refugio de carácter defensivo $\mathrm{y}$ aceptamos un uso fundamentalmente habitacional en este tipo de espacios, teniendo en consideración la multiplicidad de funciones advertidas hasta tiempos recientes. En el plano estructural, como propuesta de evolución histórica y constructiva, es posible entrever la transformación de estas cuevas-refugio en grandes complejos de viviendas con entrada a nivel de suelo y diversas alturas, hoy perceptibles en la Hoya de Guadix.

El conjunto de cuevas acantiladas domina una alquería adyacente de cierta entidad demográfica — con extensos campos de cultivo y agrosistemas irrigadoslo cual posibilita su datación cronológica y favorece otro tipo de interpretaciones. En este punto, los materiales arqueológicos dispersos en niveles superficiales son reflejo de un importante núcleo de población, cuya presencia fundamenta un uso estable y continuado de estas cuevas, lo que llevaría a descartar su consideración de refugio temporal u ocasional.

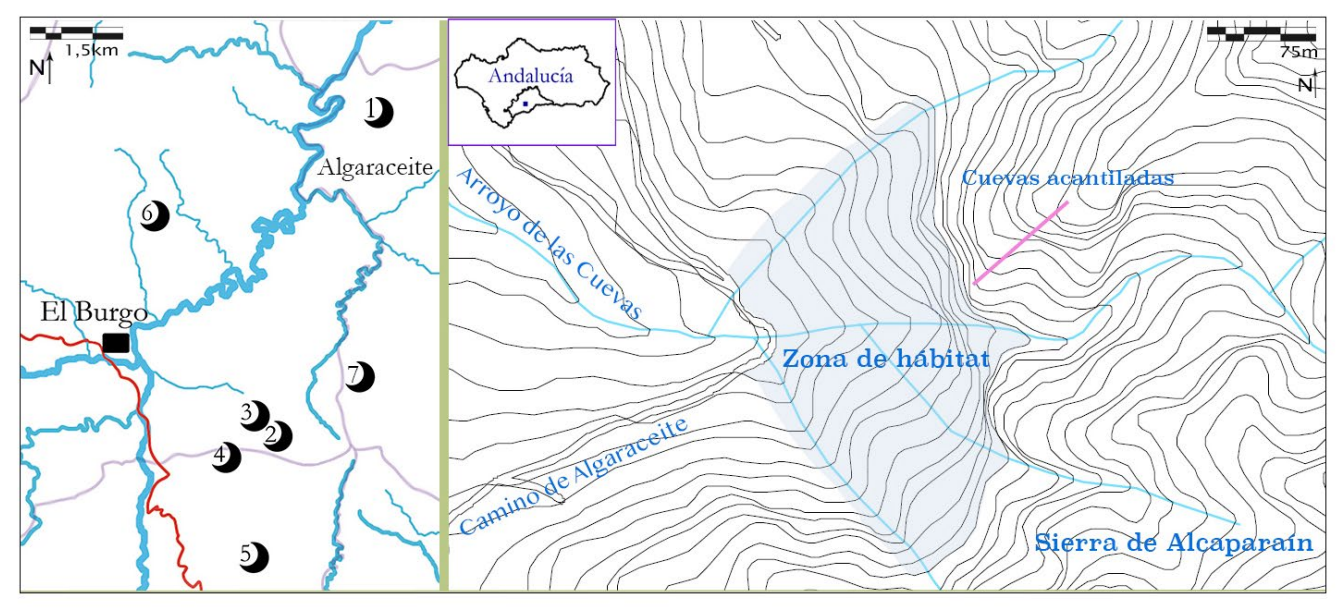

Figura 1: Localización geográfica del despoblado y perimetración del espacio de hábitat. Poblamiento altomedieval en la cuenca media del Turón: 1. Cuevas de Algaraceite; 2. Castillo del cerro de la Villa; 3. Castillo de Morototón; 4. Asentamiento en altura del peñón del Chorrito (sajra); 5. Castillejo de Labrados; 6. Alquería de Las Torrecillas; 7. Castillo de Ojo del Río

1. El yacimiento arqueológico se encuentra inédito y sin catalogar; aunque fue inventariado en las prospecciones de Ramos et al., 1990. 


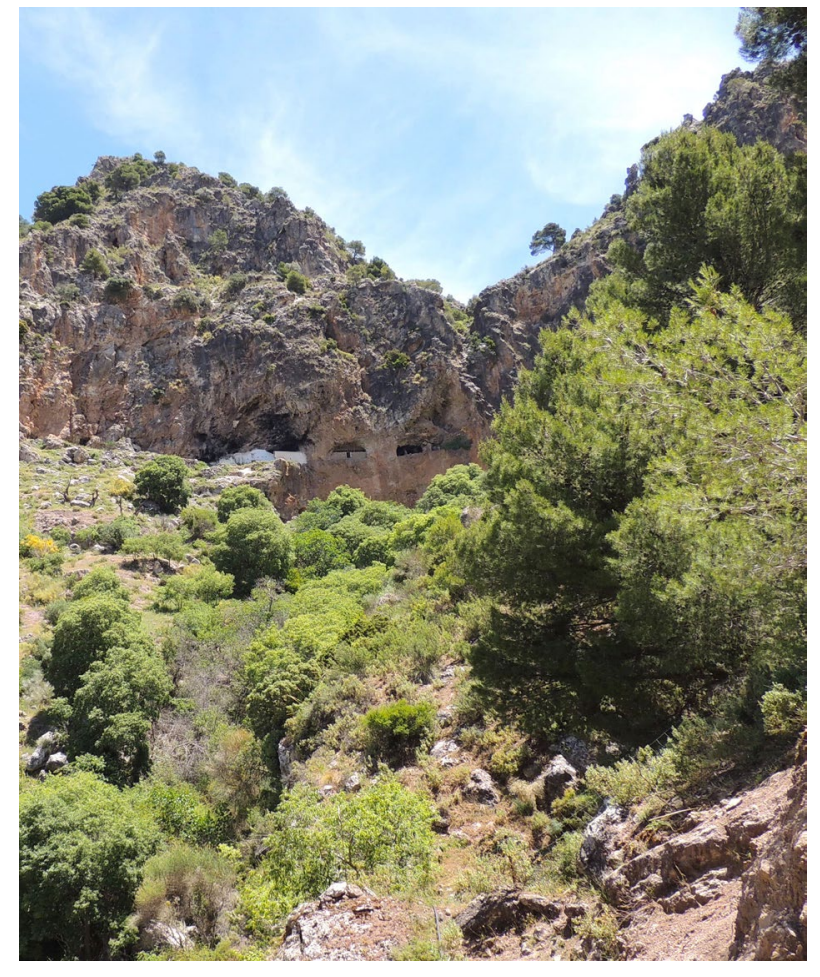

Figura 2: Vista general del yacimiento de las Cuevas de Algaraceite

El poblado se alzaba a los pies del farallón, en la margen derecha del río Turón, entre los antiguos límites territoriales de las coras de Rayya y Täkurunnā. El espacio de hábitat se encuentra dividido por el actual arroyo de las Cuevas, tributario del Turón, cuya principal surgencia tiene origen en la base del escarpe, bajo las cuevas acantiladas (Figs. 1 y 2). Su caudal se acrecienta con las aguas de escorrentía procedentes de la sierra de Alcaparaín, siendo más que suficiente para satisfacer y garantizar las necesidades hídricas del enclave (Fig. 10). De una primera aproximación arqueológica, se trataría de un asentamiento agrícola con ocupación altomedieval y continuidad en periodo bajomedieval (Fig. 7), produciéndose su abandono definitivo en el siglo XV; aunque parece innegable que las cuevas acantiladas permanecieron en uso hasta mediados del siglo pasado.

La primera noticia histórica que tenemos sobre Algaraceite consta en un tratado de tregua firmado en abril de 1439, por el que Muhammad IX, sultán de Granada, reconoce la pérdida de las plazas conquistadas por Castilla (Carriazo, 1971: 110). En este contexto fronterizo, con el objetivo de recuperar el castillo de Turón, los nazaríes acaban por reconquistar éste y la cercana alquería de Algaraceite según relata Ibn 'Āsim en su Ŷunnat al-riḍa, quien recoge el topónimo con su grafía en árabe Gār Abī Zayd ${ }^{2}$. Terés Sábada (1990:

2. Recoge la noticia Ibn 'Āsim en su Ŷunnat al-rị̄ā II: 283285. Véanse los trabajos de estudio y traducción de Charouiti Hasnaoui (1988; 1996) y Ben Driss (1995: 41-48).
184) da las claves para descifrar su etimología: nos hallamos ante la cueva del padre de Zayd, un antropónimo frecuente en la onomástica árabe, de gran difusión por la geografía de al-Andalus ${ }^{3}$, atestiguado en el cercano alfoz de Monda con la forma Garnabuzeit ( $<G \bar{a} r$ $A b \overline{\mathrm{u}}$ Zayd) $)^{4}$.

No podemos asegurar, con los datos disponibles, si el despoblado de Algaraceite llegó a tener la consideración de alquería en sentido jurídico-administrativo durante el periodo nazarí, con sus propias tierras, pastos y aguas, pues a finales del siglo XV su territorio se inscribe dentro del término de Casarabonela sin que conste haya sido anexionado; si bien tenemos claro que por entonces lindaba al norte con el término del castillo de Turón y no con el de Ardales. En este nivel de análisis, los textos históricos parecen citarlo como unidad poblacional independiente poco antes de su definitivo abandono, sin relación alguna con el alfoz de Casarabonela o de Turón.

\section{CONJUNTO PRINCIPAL DE CUEVAS}

Se compone de tres cuevas agrupadas e intercomunicadas por pequeños y estrechos pasadizos laterales, que más bien son abrigos naturales modelados para adaptarlos funcionalmente a sus diferentes usos. Se disponen en el mismo nivel de un modo simétrico, suspendidos a más de 15 metros desde la base del acantilado, controlando áreas de aprovechamiento agrícola y una de las principales vías de comunicación con el interior. Dejamos por tanto fuera de este apartado las cámaras dispersas con acceso a ras de suelo, para centrarnos únicamente en el grupo principal de cuevas, las cuales hemos enumerado para su correcta identificación en la imagen que ilustra el texto (Fig. 3).

Hasta el siglo pasado la cueva n. ${ }^{\circ} 1$ ha sido utilizada como vivienda dada su accesibilidad y dimensiones, al tiempo que la $\mathrm{n}^{\circ} 2$ ha servido para resguardar al ganado y la . $^{\circ} 3$ ha permanecido sellada, hoy sin posibilidad de acceso, razón por la cual no se ha podido estudiar el conjunto en su integridad. Junto a estas tres estancias principales tal vez pudo existir una cuarta, contigua a la n. ${ }^{\circ} 3$, cuya pared de fachada parece se haya desprendido, extremo que habrá de corroborarse en cuanto pueda accederse a su interior. Se observa también una subcámara a nivel superior con entrada cegada por la

3. Sobre el topónimo en cuestión pueden verse las publicaciones de Chavarría (1997: 25) y Martínez (2006: 226). En relación al primer elemento del topónimo, del árabe al-gār (la cueva), interesan los estudios de Martín Gutiérrez (2003: 294), Hernández (1995: 201-202) y Asín (1944: 619).

4. Archivo Histórico Provincial de Granada [AHPG], Libros de Población del antiguo Reino de Granada [LP], n. ${ }^{\circ} 6747$ (Libro de Apeo y Repartimiento de Monda). Véase transcripción completa en Urbano Pérez, 1998. 


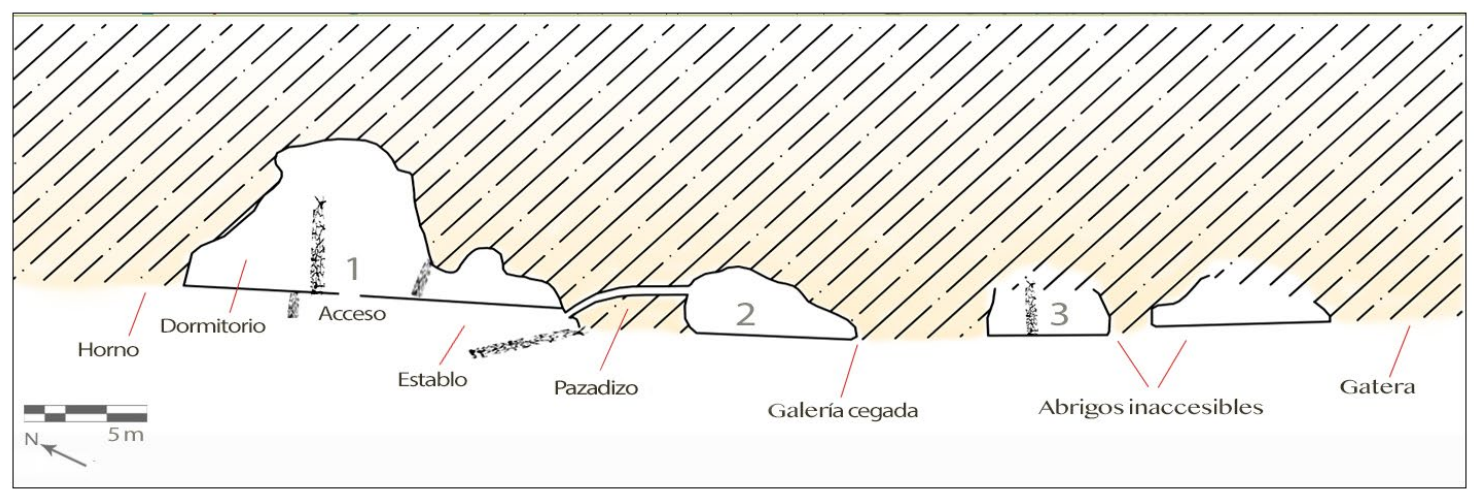

Figura 3: Esquema en planta del conjunto de cuevas

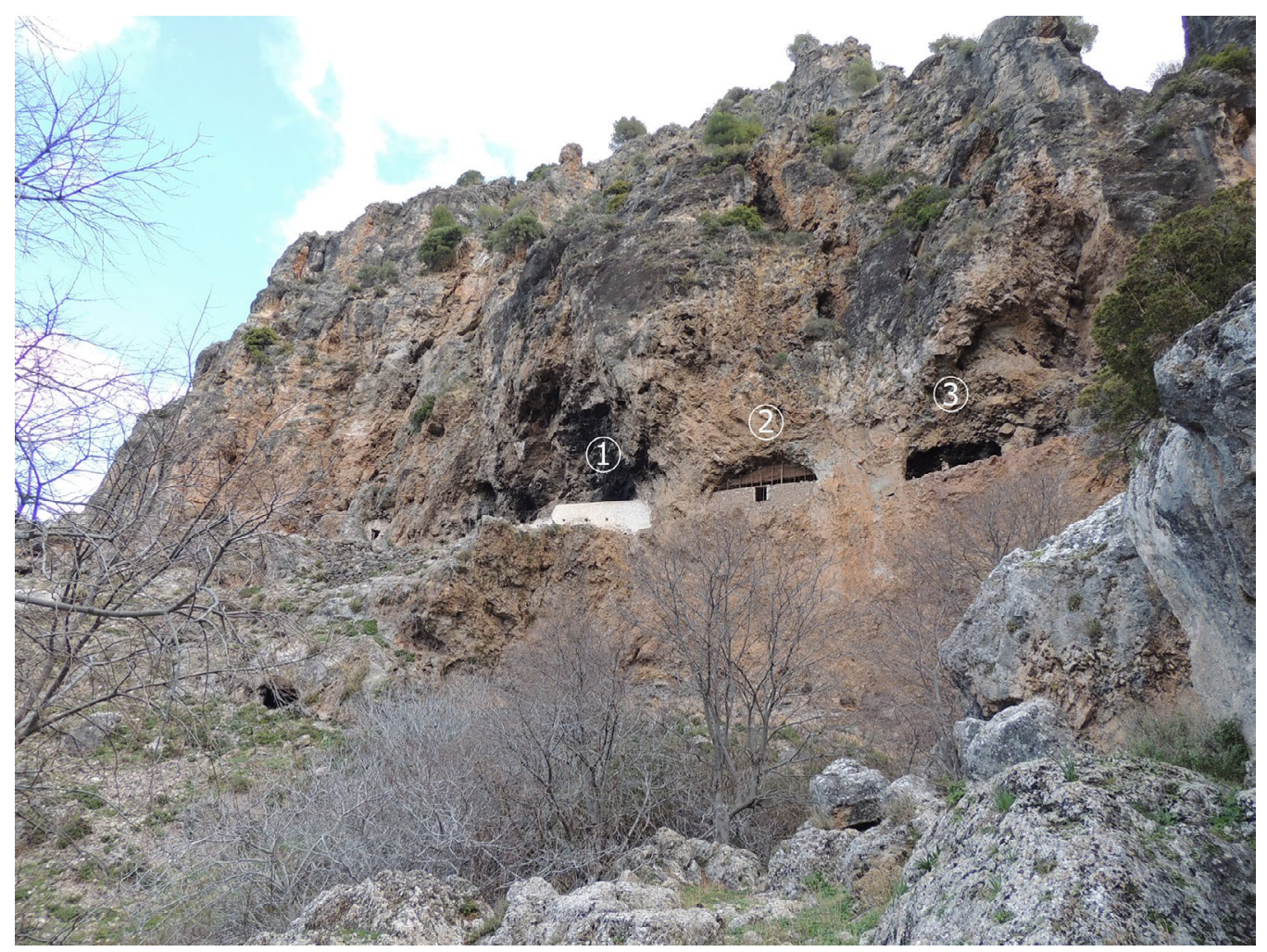

Figura 4: Conjunto principal en estudio

cueva $n .^{\circ} 1$, superpuesta a la misma, cuyas pequeñas dimensiones hacen pensar en una función de granero o atalaya (Fig. 4).

El conjunto se eleva estratégicamente en posición preeminente sobre la alquería, dominando el vado del Turón y expuesto a los vientos húmedos de Poniente procedentes del Atlántico. Se observa un desarrollo simétrico de las tres estancias en su fachada principal, que creemos pudieron cerrarse al exterior con muros de mampostería, tal y como apreciamos hoy en la cueva $n$. $^{\text {o }}$ 2. Son abrigos de escaso desarrollo, cuya morfología interna permite tanto la iluminación natural como la ventilación directa por las grandes ventanas que caen al precipicio, lo que garantiza unas condiciones mínimas de habitabilidad.

Hoy el único acceso posible al conjunto se hace por un sendero abierto entre los derrubios de ladera, que se va ensanchando en su último tramo y se contiene con muretes en seco. Sólo se reconoce este eje viario dentro de la superficie arqueológica.

\section{a) Cueva n. ${ }^{\circ} 1$}

Es la más compleja y espaciosa del conjunto, y la única que permite el acceso directo desde el exterior, reflejando un ambiente antropizado que contrasta con el resto de abrigos. Los constantes cambios de uso han modificado las estancias de interior, de manera que se hace complicado distinguir los elementos originales de los posteriores. Dado su buen acceso y dimensiones, ha estado ocupada como vivienda familiar hasta tiempos recientes, siendo el espacio más transformado del conjunto. 
La estancia original presenta divisiones internas mediante tabiques de fábrica, con aparejo de mampuestos irregulares de tamaño pequeño y mediano, resultando diferentes habitáculos de escasa ventilación, entre los que se distinguen un comedor y varios dormitorios. Su interior presenta suelos nivelados y paredes rectas, en parte revestidas con mortero y encaladas, lo que impide cualquier lectura paramental hasta el momento.

En la misma boca de acceso se aprovecha la base de un saliente natural, conservándose dos muros de cerramiento con aparejo de mampostería, ambos con distinto espesor, orientación y materiales constructivos, lo cual refleja diferentes ambientes edilicios (Fig. 3). En esta pequeña estancia exterior, anexa a la fachada principal, se levantó la cocina de obra y un horno de pan, mostrando una espesa capa de hollín en paredes y techos.

En un nivel superior a este espacio se evidencia una subcámara o silo abierto al precipicio, al cual se accedería por el interior de la cueva $n .^{\circ} 1$, quizás mediante escaleras o galería vertical, pues se observa una abertura cenital y un paso tabicado a ras de suelo justo debajo de la subcámara.

De la antigua estructura residencial sólo se reconocen las estancias subterráneas y dos muros perimetrales. Su morfología y distribución se ajustaría al módulo unicelular o sencillo (Gutiérrez Lloret, 2015: 22 y 29) pues las cuevas anejas son auxiliares, con dimensiones más pequeñas y funcionalidad diferenciada (almacén o establo), sin disponer de acceso independiente desde el exterior.

\section{b) Cueva n. ${ }^{\circ} 2$}

Ocupa una posición central en el conjunto y presenta una sola estancia de sección semicilíndrica, de escaso desarrollo y sin compartimentación visible. En el espacio interior se dan suficientes condiciones de habitabilidad, aún siendo el abrigo de menor capacidad en todo el conjunto. No existen vestigios concluyentes relacionados con la finalidad que pudo tener este espacio en periodo andalusí. En una visión de conjunto se podría pensar en una función auxiliar de la cueva $n{ }^{\circ}$ 1, por lo que no descartamos otros usos como cámara de almacenaje, aunque sus reducidas dimensiones son más que confortables para hábitat.

El abrigo apenas ha sufrido alteraciones en forma y tamaño, presentando una planta irregular de superficie cóncava. En nuestros días, la base de suelo se encuentra repleta de materia fecal, con restos óseos de especies ovicaprinas; y las paredes internas no se encuentran

\footnotetext{
5. A grandes rasgos, el módulo unicelular «se define como un volumen autocontenido y plurifuncional, una unidad de edificación con varias áreas de actividad en su interior, sin espacios subsidiarios, que constituye una unidad doméstica simple, a la que se accede directamente desde el exterior».
}

trabajadas, presentando varias capas con lechadas de cal.

Su boca frontal es una ventana de tendencia semicircular en alzado y bastante amplitud ( $3 \mathrm{~m}$ de altura), siendo inaccesible en tanto que cae al precipicio, asemejándose en parte a las denominadas cuevas-ventana del Levante peninsular, con las que guarda parecidos formales en su aspecto exterior ${ }^{6}$. Se abre en su lado cóncavo y conserva un muro de cierre de poco espesor y débil consistencia, levantado con la finalidad de resguardar al ganado.

Se accede a la misma desde la cueva $n .^{\circ} 1$ a través de un pasadizo estrecho y quebrado de apenas metro y medio de altura, lo cual, en nada facilita las tareas de introducir y almacenar los excedentes agrícolas en su interior (Fig. 5). Con la finalidad de salvar este inconveniente bien pudieron emplearse sistemas de poleas, tal como se intuye en la cueva n. ${ }^{\circ} 3$, como luego veremos. Dejando al margen los beneficios del aislamiento térmico, los niveles de humedad relativa son altos en su interior según las diversas lecturas tomadas con el higrómetro; lo cual podría afectar a la calidad y conservación de las cosechas.

\section{c) Cueva n. ${ }^{\circ} 3$}

$\mathrm{Su}$ acceso es imposible en la actualidad, bien pudo tenerlo por la cueva contigua $\left(n .^{\circ} 2\right)$ donde parece que existe una puerta lateral semienterrada de escasa altura o tal vez se pudo emplear una pasarela o escala. En este punto, se reconoce una gatera o galería hoy cegada recorriendo en paralelo el escarpe, cuya orientación hace pensar que pudo tener conexión directa con el abrigo (Fig. 3).

Se encuentra expuesta a la intemperie sin ningún muro de cierre al exterior, aunque bien parece que lo tuvo y acabó precipitándose al vacío. En su interior conserva un tabique de separación en mampostería, de poco espesor, que compartimenta la estancia en dos espacios similares. Sus techos y paredes se encuentran ennegrecidos por el humo y, aparentemente, sin restos visibles de enlucido o encalado.

La luz penetra directamente en ambas estancias por la abertura o ventana que cae al precipicio, cuyos rasgos externos guardan similitud con los graneros acantilados. Como decíamos, parece conservar una oquedad circular con restos de enlucido en el centro superior de la ventana; que cabe interpretar quizás con un mechinal de andamiaje, o tal vez perteneciera a las estructuras de pasarela. En este punto, no vamos a descartar que sirviera para encajar una vigueta con polea para levantar cargas e introducirlas en el interior de la cueva, sistema ya documentado en otros conjuntos del Levante

6. En relación a las cuevas-ventana del área levantina pueden consultarse los estudios de Ribera (2010: 358$)$ y Ribera y Bolufer (1994; 2008). 

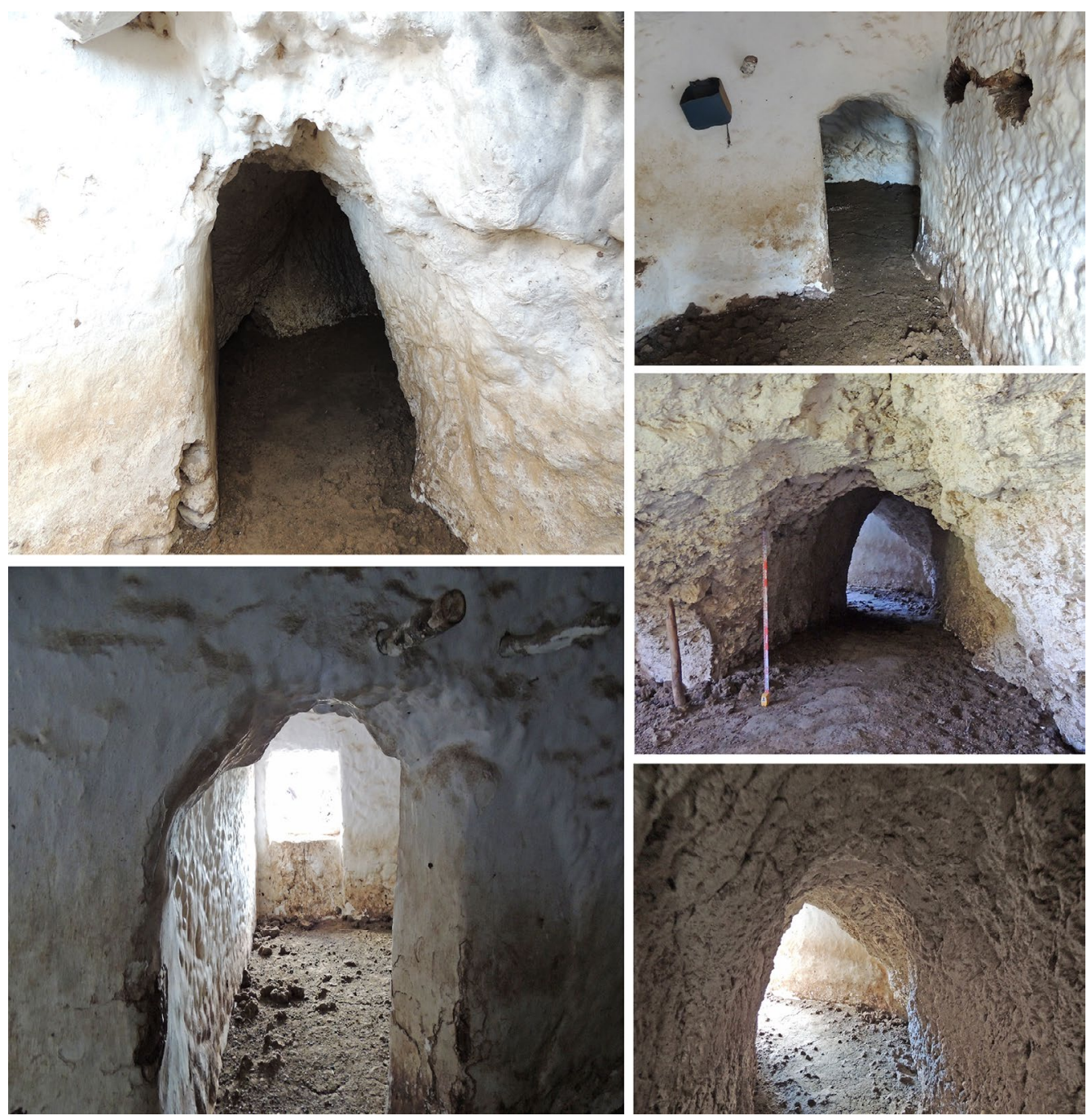

Figura 5: Detalle de los vanos y pasadizos documentados en el interior de las cuevas $\mathrm{n}^{\circ}{ }^{\mathrm{o}} 1$ y 2

peninsular (Ribera, 2010: 358; Ribera y Bolufer, 1994; 2008). Cualquier otra forma alternativa para introducir las reservas agrícolas sería compleja dada la estrechez de la galería.

Sin entrar en más detalles descriptivos, creemos que pudo beneficiarse de una cavidad dispuesta a nivel superior, imperceptible hoy por el desplome de los estratos superiores, en tanto que conserva restos de enlucido en su fachada exterior (Fig. 4). Con todo lo expuesto, resulta imposible un estudio individualizado en detalle de este abrigo hasta que no se acometan trabajos de limpieza y desenterramiento del conjunto.

\section{DIVERSIDAD FUNCIONAL}

Las cuevas de Algaraceite presentan dificultades de carácter funcional y tipológico para su inscripción en las series establecidas por Bertrand (1986; 1987a; 1990). En este punto, nuestra contribución se encuentra limitada por lo poco que se ha avanzado en la caracterización de estos conjuntos, cuya función sigue siendo una incógnita mientras carezcan de un tratamiento individualizado. Se vienen interpretando como graneros acantilados, refugios defensivos, atalayas y viviendas domésticas, entre otros usos que desechamos aquí como palomares, eremitorios, rábitas y lugares de enterramiento ${ }^{7}$.

Las cuevas en estudio conforman un conjunto único en la provincia de Málaga, sin paralelos conocidos en nuestro ámbito geográfico. En territorio de al-Andalus son contados los ejemplos inventariados que disponemos sobre cuevas acantiladas de uso habitacional o agrícola. Que sepamos, adquieren una modesta difusión en la mitad oriental peninsular, aunque nuestro objeto de estudio se aleja un tanto de estos grandes complejos:

7. En lo tocante al uso y función que tuvieron las cuevas en época andalusí son de interés los trabajos de Cano (2007a), Carmona (2012: 223-264), García Rivero et al. (2018: 119-151) y Taylor et al. (2018: 107-143). Interesa destacar la hipótesis planteada de que fuesen centros religiosos tipo rábita o zāwiya, tal es el caso de la Cueva de la Batida de Carmona (Sevilla) o el de la Cueva de la Dehesilla (Sierra de Cádiz), quizá también sea extensible al de Cueva Santa, en las cercanías de Monda (Málaga), según propuesta del arqueólogo Ildefonso Navarro. 
con varios niveles superpuestos en altura, entrada a ras de suelo y, en muchos casos, sin restos de hábitat que hagan posible su datación y caracterización.

Dentro de las muchas variantes tipológicas y funcionales propuestas, existen evidentes analogías con las llamadas «cuevas-ventana» del Levante peninsular, las cuales se vienen identificando con graneros (Ribera, 2010), aunque mayores semejanzas guardan con las «cuevas-refugio acantiladas» de la Hoya de Guadix de Granada y provincia de Almería (Bertrand, 1987a; 1987b; 1987c; 1990; 2000) ${ }^{8}$. Si nos atenemos a su distribución espacial interna podríamos encontrar coincidencias tipológicas con las documentadas en Almería, más concretamente con «las cuevas agrupadas en conjunto de tres», intercomunicadas por pequeñas puertas laterales y estrechos pasadizos, con ejemplos en Huéchar, Los Millares y Gádor. En cambio, si atendemos a la estructura y organización del poblamiento en Algaraceite, con núcleo de hábitat adyacente al conjunto de cuevas, más bien guarda semejanzas con los graneros y viviendas-refugio de Sin Salida, Marchal y Almagruz (Bertrand, 1986; 1987a; Reyes, 2011: 465477). En lo que a nosotros concierne, se vienen datando en época califal algunos complejos de Guadix como la cueva del Búho (Benalúa), el covarrón de Luchena (Purullena), el covarrón del cortijo del Capellán y la cueva de la Tía Micaela (Cortes y Graena) ${ }^{9}$.

Por las razones que venimos exponiendo, el conjunto de cuevas de Algaraceite sólo puede adscribirse a este grupo inventariado de cuevas-vivienda en acantilado. Su emplazamiento geográfico y topográfico no permite diferenciar entre un uso defensivo agrícola o habitacional, aunque atendiendo a sus rasgos formales y otros factores como temperatura, humedad, capacidad de almacenaje y profundidad de las cavidades, se hace evidente su ocupación humana de forma continuada y estable hasta el siglo pasado.

\subsection{USO DEFENSIVO Y HABITACIONAL}

El conjunto reúne condiciones óptimas para su defensa, en tanto que los accesos a las cuevas $n .^{\circ} 2$ y 3 se pueden obstruir y funcionar como unidades estancas. Ocupan el punto más estratégico del asentamiento, inaccesibles desde la base del escarpe, a menos que se empleen escalas de cuerda o madera para salvar la pared vertical. Nada impide barajar la hipótesis de que fueron cuevas fortificadas, aunque carecemos de elementos poliorcéticos por el momento. Son obvias las ventajas de buscar refugio en cuevas acantiladas: su defensa es

\footnotetext{
8. Otros complejos de cuevas acantiladas en el área andaluza han sido estudiado por Gutiérrez et al. (2005) y Cara y Rodríguez (1987).

9. En Cortes y Graena se han inventariado cuevas-viviendas acantiladas dominando la población moderna, guardando parecidos formarles con las documentadas en el Sureste de Túnez.
}

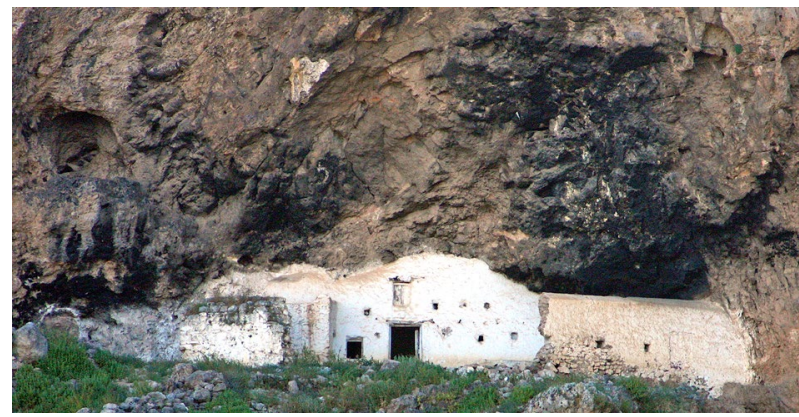

Figura 6: Estado actual del espacio destinado a vivienda (cueva n. $\left.{ }^{\circ} 1\right)$

lineal y sólo es posible un ataque frontal. Su ocupación no requiere mucho esfuerzo colectivo ni económico y se hallan mimetizadas con la naturaleza, en nuestro caso controlando una vía de intenso tráfico de personas y mercancías.

$\mathrm{Su}$ alto valor defensivo se complementa con el uso habitacional, del que no tenemos duda en el estado actual de nuestra investigación. La presencia de hollín, adherido a las paredes y techos de las cuevas laterales (n. ${ }^{\circ} 1$ y 3), delata la existencia de al menos dos hogares. Dato que está en consonancia con la capacidad de ambas estancias y con la última funcionalidad que tuvo la cueva $n .^{\circ}$ 1. El tratamiento o acabado de paredes y techos se presenta como una evidencia indirecta de su uso; pese a que se reconocen alteraciones recientes para acondicionar el primer abrigo como vivienda, mostrando sus paramentos enlucidos y encalados (Fig. 6). Por su parte, la cueva n. 2 presenta varias capas con lechadas de cal, mientras que la $n .^{\circ} 3$ sólo conserva restos de mortero alisado aplicado como revestimiento de su fachada.

Con todo, la presencia de materiales cerámicos de época alto y bajomedieval en sus inmediaciones es más que suficiente para defender un uso habitacional, acorde con la tipología y disposición de las estructuras documentadas; aunque es posible individualizar espacios con funcionalidades diferenciadas dentro del conjunto. En la zona de hábitat asociada a la alquería, los materiales de superficie se concentran al pie del acantilado, en torno al punto de captación de agua y en la cabecera del arroyo, donde son frecuentes las tejas digitadas con meandros vinculadas a estructuras domésticas, piezas que venimos documentando en contextos emirales tem$\operatorname{pranos}^{10}$. Sin embargo, en los márgenes del cauce se aprecian niveles arqueológicamente estériles por procesos de escorrentía.

De una primera aproximación al registro cerámico, los conjuntos más tempranos sólo permiten analizar sus características técnicas dado su mal estado de conservación: son pastas de poca consistencia y dureza, con gruesos y numerosos desgrasantes y cocción reductora

10. Sobre la datación de tejas en yacimientos altomedievales, véase Marmolejo Cantos (2020) y Boone (2019: 28-30). 


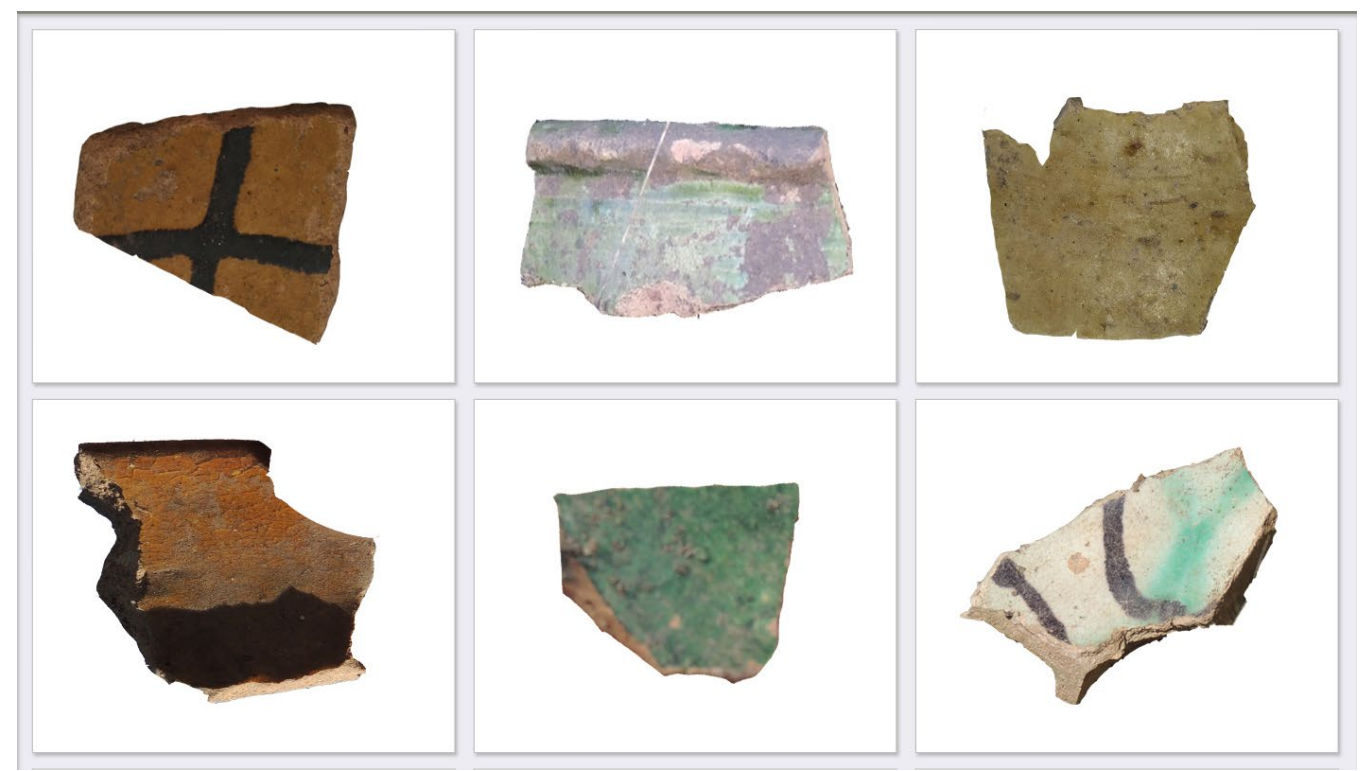

Figura 7: Vidriados islámicos asociados en superficie a los espacios domésticos de la alquería

en el núcleo ${ }^{11}$. Entre las producciones islámicas (Fig. 7), se reconocen los vidriados en verde oliva, y los melados decorados con manganeso del siglo X al XII pertenecientes a la serie ataifor. Los recipientes de cocina $y$ almacenaje asociados a las estructuras domésticas son probablemente de producción local, aunque se documentan marmitas de base plana y cuerpo ligeramente cilíndrico, con parecidos formales a los documentados en el área malagueña y murciana (Gutiérrez Lloret, 1996; 1986: 154). Su última fase de ocupación queda representada por la cerámica nazarí tardía y postmedieval. Son producciones modeladas a torno, con pastas muy depuradas y núcleos oxidados, algunas con procesos de cocción alternos. Dentro de este contexto, son frecuentes los bordes de alcadafe y los ataifores vidriados en verde claro nazarí, con perfiles semejantes a los documentados en la vega de Granada (García Porras, 2001). Vista la concentración y extensión superficial que alcanzan estos ajuares en el yacimiento, es posible evidenciar momentos de auge demográfico en periodo bajomedieval.

\subsection{USO DEFENSIVO AGRÍCOLA}

Un uso simultáneo y compatible con el defensivo y habitacional es, sin duda, el de proteger la producción agrícola en una zona de intenso tránsito, teniendo en cuenta que el cereal de secano fue la base de subsistencia y la mayor riqueza de estas comunidades instaladas en la vega media del Turón. Siguiendo esta línea de argumentación, la cueva $\mathrm{n}^{\circ} 2$ podría inscribirse en lo

11. En ausencia de contextos estratigráficos, sería interesante un análisis comparativo sobre el repertorio cerámico exhumado en cuevas de la sierra de Cádiz (Tylor et al., 2018: 107-143) y de la Subbética cordobesa (Cano, 2007b: 141-168). que se vienen denominando en Granada y Almería como «graneros acantilados», en el Levante como «cuevasventana» o en el Magreb como «greniers de falaise» ${ }^{12}$. Se viene insistiendo en el posible origen beréber preislámico de estos conjuntos, aunque existen problemas para establecer éste por falta de referentes cronológicos; hasta el momento los pocos casos estudiados en el Sur peninsular vienen arrojando una cronología almohade, con pocas salvedades.

En nuestro caso, la capacidad de los abrigos es apropiada a la función de almacenar los excedentes agrícolas; no obstante, sus estancias llegan a ser confortables y acogedoras como cualquier vivienda convencional. Además existen factores físicos limitantes para una adecuada conservación del cereal, pues no se dan las condiciones ambientales óptimas para ello. En el plano estructural, como decíamos, se aleja mucho de los grandes complejos inventariados en al-Andalus que disponen de varios niveles superpuestos en altura. En el caso específico de Algaraceite no hay fragmentación del espacio interior, ni existen subcámaras a modo de celdas o alveolos, tal se viene documentando en otros contextos geográficos (Ribera, 2010).

No son nada frecuentes este tipo de estructuras destinadas a almacenamiento, y desde luego no fue el método tradicional de conservación en nuestro ámbito geográfico, donde predominan los silos subterráneos excavados en roca, de sección piriforme, boca circular y cuerpo impermeabilizado, como observamos en Santi

12. Son las unidades de almacenamiento documentadas por Tramoyers Blasco (1899: 137-144), Montagne (1930) y Gattefosse (1934: 91-102). En proceso de estudio se encuentran algunos enclaves del Alto Atlas marroquí, en el marco del proyecto de investigación dirigido por Leonor Peña Chocarro. 


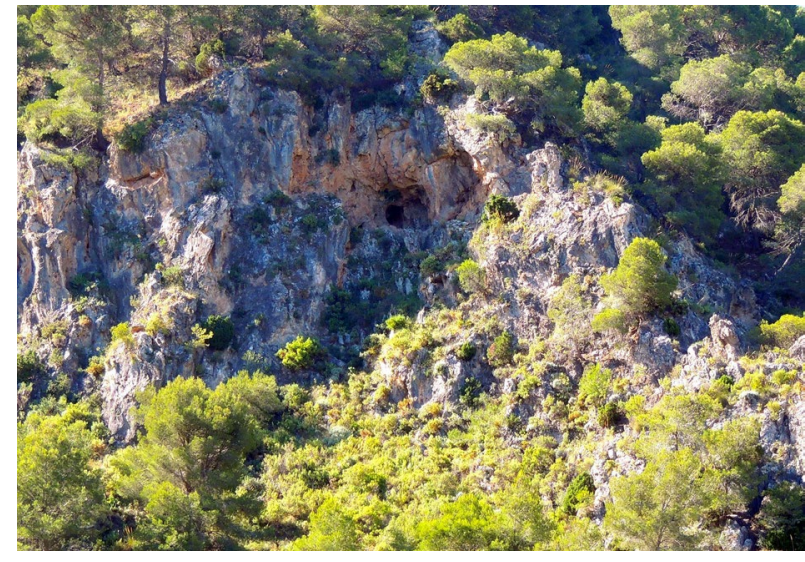

Figura 8: Abrigo acantilado situado en el límite SO de la alquería, ampliando el campo visual hacia el $\mathrm{N}$

Petri (Almogía), cortijo del Tajo (Teba) y Castillejos de Quintana (Pizarra) $)^{13}$.

No obstante, muchas de las cavidades naturales diseminadas por la alquería se integraron como parte de las estructuras domésticas y bien pudieron servir para ensilar las producciones agrícolas (Fig. 8). Igualmente se reconoce este sistema en la ciudad de Bobastro, en ciertas viviendas semirrupestres como la Casa de la Reina, que presenta una pequeña cámara de almacenaje o despensa en el nivel superior, con acceso independiente mediante escalera tallada en roca (Marmolejo Cantos, 2020). En cualquiera de los casos reseñados, ninguna de ellas tiene la consideración y uso de las cuevas-acantiladas en estudio.

\section{PROCESO HISTÓRICO: RELACIONES ESPA- CIALES Y TEMPORALES}

Algaraceite se integraba dentro de los confines de la cora de Rayya, en su extremo más occidental, no lejos de la divisoria con la circunscripción de Tākurunnā, en tanto que las poblaciones vecinas de Cañete y Teba pertenecían a esta región, ello según sugieren los estudios de Terés Sádaba (1986: 432) y Vallvé Bermejo (2004: 226). Su proximidad a Bobastro favorece que el enclave quede bajo control de Ibn Hafsūn desde los primeros momentos de la fitna de segunda mitad del siglo $\mathrm{IX}^{14}$; pero a pocos pasos del territorio bajo influencia de los Banū l-Jalī', que se extendía por ambas márgenes del curso fluvial del Guadalteba, dominando extensas

13. Castillejos de Quintana, en término de Pizarra, es un hiṣn-complejo levantado por Ibn Hafṣūn con ocupación preislámica, asociado al proceso de formación de al-Andalus, donde hemos llegado a documentar un mihrāa semirrupestre, conservando todavía buena parte del muro de la qibla, el cual datamos en periodo hafșūní atendiendo a criterios tipológicos y tecnológicos. Véase nuestro trabajo Marmolejo Cantos (2020).

14. Sobre la expansión territorial de los hafṣunníes sigue siendo esencial el trabajo de Acién (1997). superficies agrícolas destinadas al cereal de secano (Marmolejo Cantos y Cortés López, 2021: 411). Tras la descomposición del califato, continuará bajo dominio de los califas hammūdíes, posiblemente hasta que en 1056 los Banū Zīrí se hicieron con Málaga. La zona se convierte en punto estratégico para la defensa del occidente malagueño y será hostigada por la taifa de Sevilla, viviendo un periodo de gran inestabilidad e inseguridad, al jugar un papel fundamental en las conexiones entre el Mediterráneo y la campiña sevillana (Marmolejo Cantos, 2020).

En este contexto, se plantea la necesidad de examinar las relaciones espaciales entre las principales y numerosas estructuras castrales que concentra la cuenca media del Turón (Fig. 1), donde se alzaban los castillos altomedievales del Cerro de la Villa, Morototón (El Burgo) y Ojo del Río (Casarabonela), a los que podemos añadir la șajra del peñón del Chorrito (Yunquera). Habrá que significar que todos estos enclaves defensivos se localizan en un radio inferior a $\operatorname{los} 2 \mathrm{~km}$ y se levantan en torno a la ruta comercial que se dirige a Ronda remontando el Turón por El Burgo ${ }^{15}$ y el castillo de Lifa ${ }^{16}$. Desde planteamientos arqueológicos, el castillo del Cerro de la Villa pasa por ser el hiṣn de mayor complejidad y entidad demográfica. La extensión del recinto amurallado y el registro material apuntan a una alquería fortificada en altura, que sin duda fue el centro rector del poblamiento en estudio, contando con varias poblaciones asociadas, la de mayor importancia al $\mathrm{N}$ del castillo de Morototón ${ }^{17}$.

En periodo bajomedieval, el modelo de poblamiento en la zona, basado en alquerías y agrosistemas, pasa a ser regido por las grandes fortalezas de El Burgo, Turón y Ardales. Desde un enfoque arqueológico y espacial, se percibe un alto grado de ocupación en la vega media del curso fluvial; aunque se abandonan las estructuras castrales y los muchos enclaves en altura (Fig. 1) ${ }^{18}$. Sólo van a pervivir las antiguas alquerías cercanas al río, de clara vocación agrícola, junto a otros establecimientos de nueva creación (Fig. 9). En este contexto histórico, desde el siglo XII en adelante, se

15. Esta vía de comunicación se bifurcaba en la fortaleza de El Burgo con dirección al puerto de los Empedrados y del Viento para alcanzar la ciudad de Ronda.

16. En Lifa documentamos una pequeña fortaleza altomedieval que, tras su abandono, se convierte en torre vigía de la frontera castellano-nazarí. La importancia histórica de este puesto defensivo y del camino de Lifa, que va de Málaga a Ronda, se documenta en la conocida batalla de Lopera, conservándose restos de un puente de origen andalusí tras rebasar el puerto de la Mujer. Véase Historia de los hechos de Don Rodrigo Ponce de León, 1893: 224-225.

17. Otra de ellas es la alquería de Cohetia o Çofrirar, citada en el deslinde entre la tierra de Málaga y Ronda de fines del siglo XV, que quizá se corresponda con la șajra del peñón del Chorrito (T. M. de Yunquera).

18. Sólo el cercano castillo de Morototón (Motoltrotón) continua con hábitat residual en periodo bajomedieval, según refleja el registro cerámico superficial. 


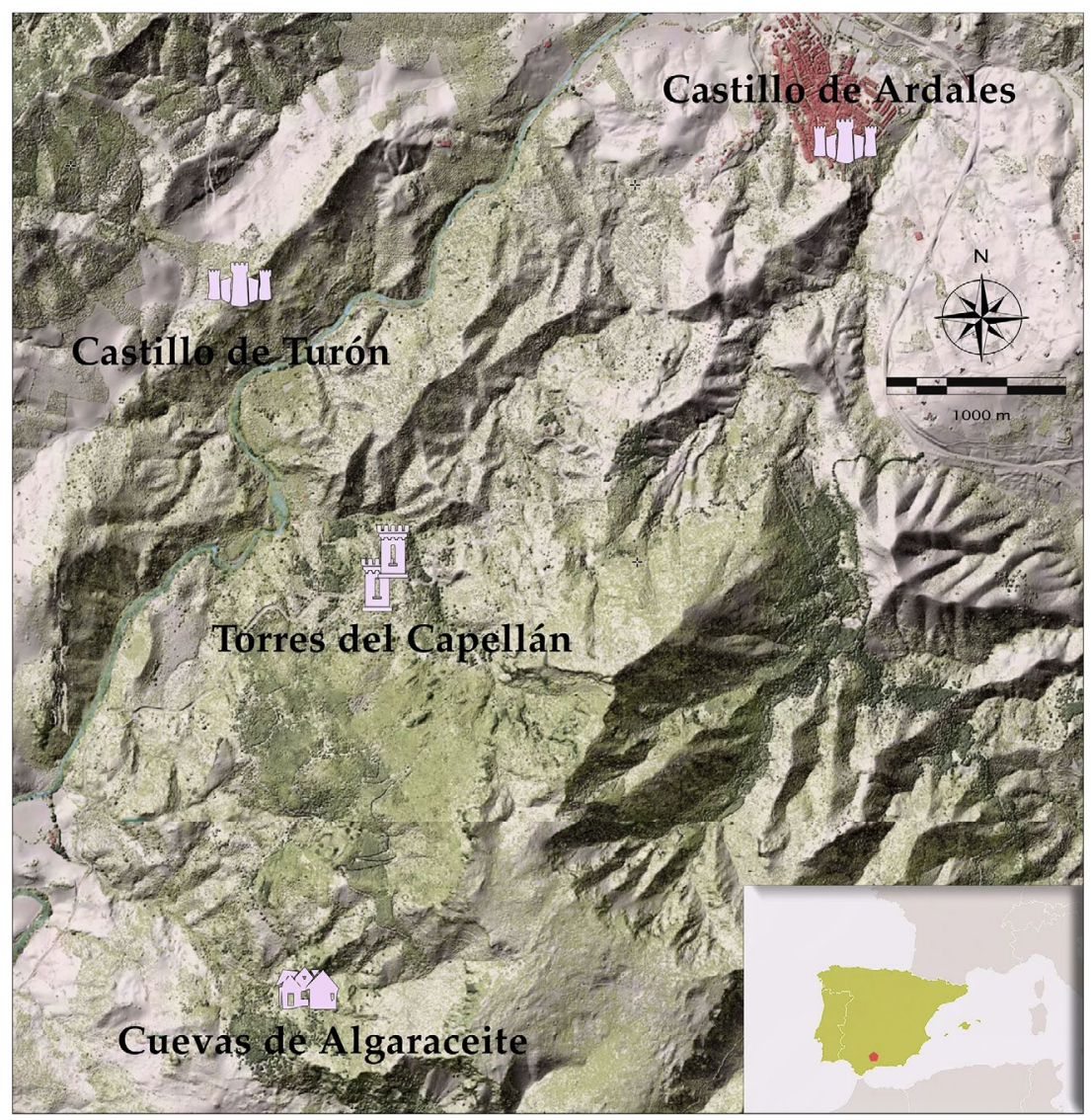

Figura 9: Poblamiento bajomedieval asociado al țagr de Turón

reconocen formas de hábitat disperso en ambas márgenes del cauce: Algaraceite, El Capellán, Ardales, El Burgo, Torrecillas ${ }^{19}$ y Turón ${ }^{20}$. Considerando esta densa red de alquerías, podríamos hablar de un proceso de concentración poblacional de origen andalusí en la vega fluvial; aunque más bien habría que replantearse un proceso de colonización rural de zonas marginales, tal vez auspiciado por el Estado almohade, en la línea propuesta por Azuar (2004) para las franjas costeras de al-Andalus.

La cercana población de El Burgo aparece como nudo principal de comunicaciones en la obra del geógrafo al-Idrī̄sī (Abid Mizal, 1989), proporcionando diversos itinerarios donde dicha alquería es punto final de etapa y parada obligada en desplazamientos de larga distancia. Desde puerto Martina, paso natural entre las

19. Sobre el yacimiento de las Torrecillas y el poblamiento medieval vinculado al castillo de El Burgo véanse los trabajos de Gozalbes Cravioto (2003; 2005).

20. La fortaleza de Turón parece conjugar obras vinculadas al aparato de época almohade y nazarí, con una evolución constructiva similar a la ya advertida en el castillo de Monda. Se percibe el lenguaje oficial desarrollado por el Estado almohade, además del programa de refortificación llevado a cabo por el emir Muhammad V hacia la segunda mitad del siglo XIV, bien caracterizado por emplear mampuestos regulares de tamaño medio, dispuestos en perfectas hiladas horizontales y recalzados profusamente con lajas y ripios. sierras Prieta y Alcaparaín, se llegó a controlar un eje de comunicación de especial valor estratégico para alcanzar el Mediterráneo. Esta importante ruta comercial, ya documentada como vía romana por Gozalbes Cravioto (1987), se bifurcaba hacia las tierras de Algaraceite vadeando el río Turón para atravesar el puerto de la Ferradura, con acceso directo a las tierras de Ortegícar y Cañete.

En periodo nazarí la alquería de Algaraceite se inserta en el occidente del reino granadino y pasa a ser un enclave estratégico en las continuas disputas con los reinos cristianos, cortando el acceso a las incursiones castellanas que avanzan desde el puerto de la Ferradura hacia el paso obligado de Martina. Durante los siglos XIV y XV, cuando el territorio queda militarizado dada su posición fronteriza, todo hace indicar que la zona va a quedar despoblada; aunque nuestra alquería vendrá a desempeñar un papel más activo, visto el protagonismo histórico que va adquiriendo en las fuentes textuales. El proyecto de cruzada de Alfonso XI acabó fracasando, aunque el monarca logró conquistar las plazas nazaríes de Teba, Cañete, Priego y las torres de Ortegícar y Las Cuevas (¿de Algaraceite?) en el verano de 1330. El visir Riḍwān las recuperó en el invierno de 1349; con la salvedad de la fortaleza de Teba, plaza que no volverán a recuperar jamás, quedando como punta de lanza en territorio nazarí. No mucho después, todas las fortalezas de la Hoya de la algarbía malagueña, situadas entre el Guadalteba y el Guadalturón, fueron reconquistadas 
por Pedro I en 1362 y estuvieron cuatro años en poder del monarca castellano ${ }^{21}$, pero el sultán Muhammad V las volvió a recuperar en la primavera de 1366.

En este contexto fronterizo, la importancia de Algaraceite en el control y vigilancia de los puertos de montaña, con conexión directa al valle del Guadalhorce, queda reflejada en una cabalgada del maestre de Santiago desde el castillo de Ortegícar hasta el Val de Cártama, que atraviesa el paso de la Ferradura y vadea el Turón, enumerando las diferentes poblaciones que encuentran a su paso, entre las que se incluyen El Burgo, Turón, Ardales y las cuevas Cojaf ${ }^{22}$.

Las cuevas de Algaraseyte son citadas expresamente en el tratado de treguas de 1439 entre Castilla y Granada, donde se enumeran las últimas villas y lugares ganados por los castellanos en territorio granadino (Amador de los Ríos, 1879; Carriazo, 1971: 110) ${ }^{23}$. Sin embargo, apenas unos años después, relata Ibn 'Āsim (Ŷunnat al-riḍa II: 283-285) que el alcaide de Málaga, Abū 1-'Abbās Aḥmad ibn 'Abd al-Barr, reconquistó el castillo de Turón y Gār Abī Zayd (Algaraceite), de los cuales los cristianos se apoderaron en 1432 durante la

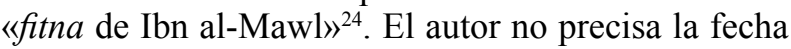
de su recuperación, pero se puede deducir del texto que el suceso tuvo lugar poco después de 1447 (Ben Driss, 1995: 41-48).

Datos geográficos de interés ofrece el deslinde de 1491 entre los términos de Casarabonela y el Burgo, que va siguiendo el arroyo de las Doncellas hasta su confluencia con el Turón y el arroyo Blanquillo, «que viene de la Ferradura, en derecho de las cuevas de Algaraseyt» (López de Coca, 1975: 545) ${ }^{25}$. Asimismo, en los repartimientos de finales del siglo XV aparecen menciones

21. Ibn al-Jațîb nos dice que el tirano (Pedro I) llegó a la fortaleza de Cañete, que (re)conquistó el visir Riḍwān (en 1349), y la ocupó; luego se trasladó al distrito de Turón.

22. Detalles de esta incursión castellana encontramos en la Crónica de Juan II de Castilla, 1982: 161.

23. En su larga relación aparecen Huéscar, Benialamar, Beniamaurel, Cañete, Alcalá, Galera, Torralva, Castilleja, Orce, Veles el Rubio, Veles el Blanco, Teireza, Segura, El Box, Ximena, Castellar, Fardales, Las Cuevas, Vélar, las Cuevas de Algaraseyte, las Cuevas de Juan Francisco, las Torres de las Cuevas de Juan Francisco, Turón, Zixna, Isnaxar, Pesquera, la Torre de Ruti, las Cuevas de Belda, Huelma, Arenas, Béxix, Solera, la Torre del Oralín y la Torre del Lusero, con todos sus términos.

24. Recoge la noticia Ibn 'Āsim, Ŷunnat al-riḍa, II: 283-285. Véase traducción en Charouiti Hasnaoui $(1988 ; 1996)$. El dato aparece publicado en Ben Driss (1995: 41-48) y Martínez (2006: 226); ambos historiadores desconocen la ubicación concreta del yacimiento en estudio aunque, como hipótesis de trabajo, lo intuyen cercano al castillo de Turón.

25. Archivo Catedral de Málaga [ACM], Leg. 56, Cuadrante 38, también puede consultarse en Archivo Municipal de Málaga [AMM], Libro de Actas Capitulares, vol. 1, fols. 99 y ss. En el deslinde de Casarabonela de 1575 se cita un castillejo a los pies de la sierra de Alcaparaín, en la margen derecha del Turón, que podría identificarse con Algaraceite (Marmolejo Cantos, 2014: 4); aunque no se puede descartar que haga expresas al arroyo de las cuevas de Algarazeyte (hoy arroyo de las Cuevas) ${ }^{26}$, cuya surgencia tiene lugar en el mismo yacimiento, concretamente en el interior de una concavidad natural medio cegada, dividiendo el espacio de hábitat y de trabajo en dos mitades (Fig. 1). Sus aguas eran conducidas por atanores al interior de una alberca de planta rectangular, hoy en ruinas, donde se almacenaba para abastecimiento humano y ganadero ${ }^{27}$. Del mismo punto de captación partía otro ramal con dirección al espacio irrigado adyacente al despoblado. Se trata de un sistema hidráulico de reducidas dimensiones aún en funcionamiento, diseñado para unas pocas familias y no apto para toda una población; de ahí que sus individuos posiblemente se vieran abocados a usar los sistemas fluviales del río Turón.

Dentro del marco productivo asociado al enclave, los textos refieren tierras de secano, espacios irrigados y un molino de época andalusi ${ }^{28}$. De su excelente situación geoestratégica, dan cuenta las numerosas referencias al vado y venta del Turón, «cerca de las cuevas de Algarazeyte», junto a una isla del Guadalturón, posiblemente originada por los sinuosos meandros de su cuenca media ${ }^{29}$. Se distinguen tres sistemas hidráulicos de captación fluvial que alteraron el trazado del cauce en su tramo medio, posiblemente, debido a la deforestación de las zonas de ribera y la construcción de presas para la derivación de aguas. La morfología actual del cauce fluvial, sin esquivar las variaciones hidrológicas, puede deberse en gran parte a los cambios en los usos agrícolas del suelo para la puesta en regadío. Ello se evidencia aguas arriba de su curso, ya desde época andalusí, en la densa red de acequias de El Burgo, Casarabonela y cortijo del Turón.

Hoy se conserva un plano histórico donde se delimita el espacio irrigado de Algaraceite y los términos propios de estos poblados ${ }^{30}$, haciendo posible el estudio comparativo del trazado fluvial y su evolución; al tiempo que permite identificar los primeros cortijos y sistemas hidráulicos de la zona (Fig. 10). En el mismo, interesa llamar la atención sobre las acequias más antiguas de morfología arborescente (andalusíes), en contraposición con las nuevas conducciones de origen castellano, que forman ángulos rectos en sus tomas de

referencia a las torres del Capellán (TM. de Ardales), despoblado de la margen derecha del Turón limítrofe con Algaraceite.

26. AMM, LR IV, fols. $52 \mathrm{v}, 79,79 \mathrm{v}, 83 \mathrm{v}, 85$.

27. La alberca en proceso de estudio conserva una escalera con peldaños de piedra encastrados al muro exterior, con el fin de facilitar las tareas de mantenimiento y reparación.

28. AMM, LR IV, fols. $52 \mathrm{v}, 79,79 \mathrm{v}, 83 \mathrm{v}, 85$.

29. «Un sitio de molino e otro de venta al río de Guadalturón, a las paredejas, junto con el vado e cerca de las cuevas de Algarazeyte, que es término de Caçarabonela alinde del término de Turón». AMM, LR V, fol. 275.

30. Archivo de la Real Chancillería de Granada, SF-4 (MPD n. $\left.{ }^{\circ} 19\right)$. 


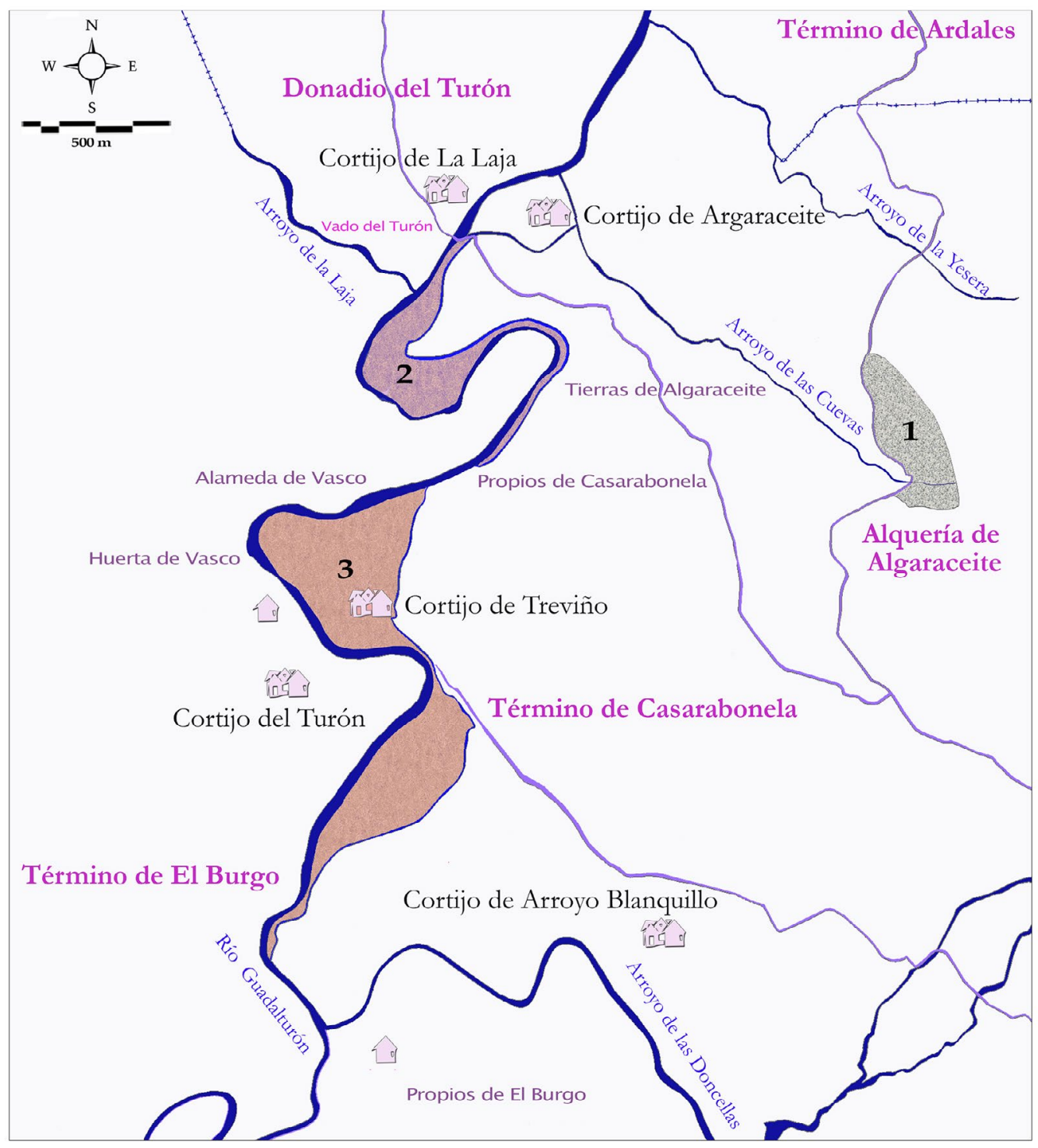

Figura 10: Espacio de hábitat y trabajo. 1) Despoblado de las Cuevas de Algaraceite; 2) Espacio irrigado de Algaraceite; 3) Espacio irrigado de los labradores de Casarabonela

derivación, precisamente en la línea propuesta para la huerta valenciana por Guinot y Esquilache (2010).

\section{A MODO DE CONCLUSIÓN}

De los datos que nos transmiten los textos podríamos aceptar que el grupo de cuevas de Algaraceite pertenecía en propiedad a un individuo cuya identidad histórica ignoramos, que lleva la kunya árabe $A b i ̄$ Zayd y es conocido por ella sin ningún otro elemento onomástico. Nos hallamos ante un personaje de relevancia dentro de la estructura social de su tiempo, pues su nombre va a pervivir bajo los sucesivos propietarios, incluso va a designar a la alquería adyacente. De por sí, la kunya es un elemento de distinción y prestigio: sólo los musulmanes libres pueden llevarla y responde a un programa de equiparación entre árabe y musulmán. No es apropiado dirigirse a una persona respetable por su ism, lo correcto es hacerlo por la kunya y así se hace en la cancillería (Cervera Fras, 1991: 233).

De un análisis espacial y funcional sobre el conjunto de cuevas, considerando que ocupan una posición central y preeminente sobre la alquería a la que da nombre, podríamos establecer cierta relación jerárquica con respecto al resto de las estructuras domésticas; y por ello, entrando a valorar posibles diferencias sociales, habría que replantearse si nos hallamos ante una vivienda asociada a la elite local.

Entre los restos visibles, a falta de un análisis estratigráfico sobre los depósitos y estructuras, se puede reconocer cierta especialización funcional en las estancias conservadas, quedando las cuevas $n .^{\circ} 1$ y 3 destinadas a residencia y la $\mathrm{n}^{\circ} 2$ como espacio de almacenaje o establo. Se constata que todas ellas comparten el mismo acceso, posiblemente usado como espacio común, y se reconocen dos áreas de combustión, una al exterior de la cueva n. $^{\circ} 1$ y otra al interior de la n. ${ }^{\circ}$ 
3. Hasta el momento, no hay evidencias claras de un grupo familiar extenso vista la reducida capacidad del conjunto. No obstante, la interpretación más razonable sugiere que, tanto $A b \bar{\imath}$ Zayd como sus descendientes fueron quienes habitaron estas cuevas acantiladas; y que estos debieron ostentar propiedades dentro de la alquería, así como tierras irrigadas en la margen derecha del río Turón. Por lo demás, no poseemos indicadores materiales para afirmar una organización social de tipo segmentario en sentido antropológico. La morfología de este tipo de estructuras domésticas «no permite una traducción mecánica en términos de etnicidad» (Gutiérrez Lloret, 2015: 22 y 29). Y tampoco tenemos datos precisos sobre la organización clánica del espacio agrícola, más allá de la asignación de las aguas del Turón, que se reparten y distribuyen entre tres alquerías limítrofes mediante acequias independientes.

En todo caso el topónimo Algaraceite, aplicado concretamente a las cuevas, no va referido a una colectividad; sino que más bien vendría a identificar al propietario que las habitó, por ello debemos postular un uso privativo del conjunto, al menos en periodo bajomedieval $^{31}$. Ciertamente se registran varios topónimos gentilicios en los repartimientos de Casarabonela del siglo XV, así como en sus deslindes y apeos del siglo XVI (Areces, 1993: 17-20; Chavarría Vargas, 1997) ${ }^{32}$; pero estos van referidos fundamentalmente a la vega de Río Grande y La Jara y, en rigor, tampoco se sabe en qué momento quedaron fijados, por lo que nada aportan a la datación o caracterización étnica del espacio geográfico en estudio.

En último término, el conjunto de cuevas de Algaraceite podría encajar, no sin problemas y matices, en las series tipológicas elaboradas por Bertrand (1986) en la Hoya de Guadix, guardando ciertas semejanzas funcionales con las cuevas-refugio en acantilado y algunos graneros fortificados de carácter troglodítico ${ }^{33}$. Aún así las diferencias son notables en sus aspectos formales y espaciales: aquí no existen niveles superpuestos en altura, tampoco disponen de entrada a ras de suelo, ni son cuevas aisladas al margen de toda unidad poblacional. En nuestro caso existe una alquería

31. Su primera aparición tiene lugar en las fuentes escritas castellanas y nazaríes del siglo XV. Se ha mantenido vigente en fuentes cartográficas hasta principios del XIX y hoy pervive en plural en títulos de propiedad como partido rural (Algaraceites).

32. Transcripción completa de los repartimientos de Casarabonela se encuentra en Bejarano Pérez (1974). El deslinde inserto en los apeos (AHPG, LP n. ${ }^{\circ} 6467$, fols. 346 r y 347 v) puede consultarse en Marmolejo Cantos (2014).

33. En último término, un posible uso como granero sólo es perceptible como complementario al habitacional por las razones expuestas. De cualquier modo, es incuestionable su uso como refugio habitacional, agrícola y ganadero hasta tiempos recientes. De hecho, en la actualidad pasa por ser refugio de pastores y, hasta el siglo pasado, la cueva ${ }^{\circ} .^{\circ} 1$ se vino utilizando como vivienda familiar y la $n .^{\circ} 2$ para resguardar el ganado. de cierta entidad demográfica adyacente al conjunto, citada expresamente en los textos históricos árabes, que permite su datación cronológica e interpretación, a diferencia de lo que ocurre en otros muchos contextos arqueológicos. En este punto, del estudio que presentamos, cabe plantear como hipótesis que las tipologías inventariadas en Guadix podrían obedecer a la evolución de conjuntos más simples como el de Algaraceite.

\section{REFERENCIAS}

Acién Almansa, M. (1997). Entre el Feudalismo y el Islam. Umar Ibn Hafsún en los historiadores, en las fuentes y en la historia. Jaén: Universidad de Jaén.

Al-Idrīsī. Uns al-muhây wa-rawd al-furây, trad. en Los caminos de al-Andalus en el siglo XII, según "Uns al-muhaŷ wa-rawd al-furaŷ" (Solaz de corazones y prados de contemplaciones). (Estudio, edición, traducción y anotaciones por Jassim Abid Mizal. Prólogo de M. Jesús Viguera. 1989). Madrid: CSIC

Amador de los Ríos, J. (1879). Memoria histórico-crítica sobre las treguas celebradas en 1439 entre los reyes de Castilla y de Granada. Memorias de la Real Academia de la Historia, IX. Madrid: Real Academia de la Historia.

Areces Gutiérrez, A. (1993). Contribution au lexique araboandalou: un document roman de l'Andalousie orientale. Hespéris-Tamuda, XXXI, 9-20. Recuperado de: http://www. hesperis-tamuda.com/3/data/archives/Hesp $\%$ C3\%A9risTamuda\%201993.pdf

Asín Palacios, M. (1944). Contribución a la toponimia árabe de España. Madrid: CSIC.

Azuar Ruiz, R. (2004). Campesinos fortificados frente a conquistadores feudales en los valles del Vinalopó. En J. Jover Maestre y C. Navarro Poveda (Eds.). De la Medina a la Vila. II Jornadas de Arqueología Medieval (Alicante, 2004) (pp. 263-291). Alicante: Excma. Diputación Provincial - Centre d'Estudis Locals del Vinalopó.

Bejarano Pérez, R. (1974). El Repartimiento de Casarabonela. Estudio y transcripción. Málaga: Instituto de Cultura, Diputación Provincial de Málaga.

Ben Driss, A. (1996). La frontera granadino-castellana en la primera mitad del siglo XIV. En F. Toro Ceballos y J. Rodríguez Molina (Coords.). Estudios de Frontera. Alcalá la Real y el Arcipreste de Hita (Alcalá la Real, 1995) (pp. 41-48). Jaén: Diputación Provincial de Jaén. Recuperado de: https://medievalistas.es/la-frontera-granadino-castellana-enla-primera-mitad-del-siglo-xv/

Bertrand, M. (1986). El hábitat troglodítico antiguo en la Hoya de Guadix. Elementos de tipología. En Actas del Coloquio sobre Arqueología Espacial. Época romana y medieval (Universidad de Teruel, 1986) (pp. 263-283). Teruel: Universidad de Teruel.

Bertrand, M. (1987a). Las cuevas artificiales medievales y su relación con la estructura de poblamiento en la Hoya de Guadix (Granada). Anuario Arqueológico de Andalucía/1985, Actividades Sistemáticas, t. II, 185-192. 
Bertrand, M. (1987b). Los covarrones-refugio de Guadix: primeros datos cronológicos. En II Congreso de Arqueología Medieval Española (Madrid, 1987) Tomo II (pp. 451-465). Madrid: Comunidad de Madrid.

Bertrand, M. (1987c). Cuevas artificiales y estructuras de poblamiento medievales de la Hoya de Guadix (Granada). Anuario Arqueológico de Andalucía/1986, Actividades Sistemáticas II, 236-241.

Bertrand, M. (1990). Trogloditismo artificial y estructuras medievales de poblamiento de la Hoya de Guadix. Estudios comparativos con otras zonas de Andalucía oriental. Anuario Arqueológico de Andalucía/1987, Actividades Sistemáticas II, 200-206.

Bertrand, M. (2000). Cuevas d'al-Andalus et cuevas chrétiennes. Origine et évolution de l'habitat troglodytique des hauts plateaux de Grenade. En A. Bazzana y É. Hubert (Dirs.). Castrum 6. Maisons et espaces domestiques dans le monde méditerranéen au Moyen Âge (pp. 27-52). Collection de la Casa de Velázquez, 72. Roma - Madrid: Casa de Velázquez.

Boone, J. L. (2019). La organización de los asentamientos rurales en relación con la formación del califato en alAndalus: el caso del Alentejo portugués. En M. M. Delgado Pérez y L. G. Pérez-Aguilar (Dirs.). Economía y trabajo. Las bases materiales de la vida en al-Andalus (pp. 17-42). Sevilla: Alfar.

Cano, E. (2007a). La ocupación de cuevas naturales durante la Edad Media andalusí en el entorno de Madinat Baguh (Priego de Córdoba). Granada: Alhulia.

Cano, E. (2007b). Formas cerámicas representativas de la ocupación de cuevas naturales, durante la Edad Media andalusí, en el entorno de Madinat Baguh (Priego de Córdoba). Antiquitas, 18-19, 141-168.

Cara Barrionuevo, L. y Rodríguez López J. M. (1987). Introducción al estudio de las cuevas artificiales medievales de la provincia de Almería. Boletín de Instituto de Estudios Almerienses. Letras, 7, 25-48. Recuperado de: http://www. biblioarqueologia.com/articulo.php?id=280

Carmona, R. (2012). Ascetas, devotos y misticismo islámico: nuevas perspectivas sobre la ocupación de cuevas naturales en madinat Baguh (Priego de Córdoba). Antiquitas, 24, 223-264.

Carriazo y Arroquia, J. de M. (1971). En la frontera de Granada. Sevilla: Universidad de Sevilla.

Cervera Fras, M. ${ }^{a}$ J. (1991). El nombre propio árabe medieval. Sus elementos, forma y significado. Aragón en la Edad Media, 9, 225-242.

Charouiti Hasnaoui, M. (1988). Edición y estudio del Kitāb $\hat{Y} u n n a t$ al-rid̄a de Ibn 'Āsim de Granada. (Tesis doctoral inédita). Universidad Complutense. Madrid.

Charouiti Hasnaoui, M. (1997). La intervención de la mujer en la vida política granadina durante la primera mitad del siglo XV. En F. Toro Ceballos y J. Rodríguez Molina (Coords.). Estudios de Frontera. Alcalá la Real y el Arcipreste de Hita (Alcalá la Real, 1995) (pp. 323-334). Jaén: Diputación Provincial de Jaén.
Chavarría Vargas, J. A. (1997). La toponimia árabe del repartimiento de Casarabonela: aproximación a su estudio. Jábega, 77, 11-31.

Crónica de Juan II de Castilla. (Edición de J. de M. Carriazo, 1982). Madrid: Real Academia de la Historia.

García Porras, A. (2001). La cerámica del poblado fortificado medieval de «El Castillejo» (Los Guájares, Granada). Granada: Athos-Pérgamos.

García Rivero, D., Taylor, R., Pérez Aguilar, L. G., Pérez Jordà, G., García, E., López, J. A.,... y Bernáldez, E. (2018). Andalusi populations at La Dehesilla Cave (Sierra de Cádiz, Southern Iberia): an interdisciplinary approach to their rural economic systems. Journal of Islamic Archaeology, 5(2), 119-151. DOI: https://doi.org/10.1558/jia.36443

Gaspariño García, S. y Benito de los Mozos, F. (2011). Nota sobre una nueva ceca para las monedas nazaríes: Ronda. Ensayo de su atribución. Omni, 3, 63-69. Recuperado de: http://www.wikimoneda.com/OMNI/revues/OMNI_3_fr.pdf

Gattefosse, J. (1934). Les greniers de falaise, forme ancienne d'agadir collectif. Bulletin de la Société de Préhistoire du Maroc, VII, 91-102.

Gozalbes Cravioto, C. (1987). Las vías romanas de Málaga. Madrid: Colegio de Ingenieros de Caminos, Canales y Puertos.

Gozalbes Cravioto, C. (2003a). Hallazgos de amuletos de plomo andalusíes en la provincia de Málaga. En Actas del III Congreso de Historia de Andalucía, Andalucía Medieval I (pp. 343-362). Córdoba: Cajasur, Obra Social y Cultural.

Gozalbes Cravioto, C. (2003b). Una moneda inédita hallada en la alquería medieval de Fuente Cherino (El Burgo). Turóbriga, 7, 33-36.

Gozalbes Cravioto, C. (2005). Un curioso amuleto medieval de Las Torrecillas (El Burgo). Turóbriga, 9, 97-99.

Guinot, E. y Esquilache, F. (2010). Moncada i l'Orde del Temple en el segle XIII. Una comunitat rural de l'Horta de València en temps de Jaume I. Valencia: Institució Alfons el Magnànim.

Gutiérrez Lloret, S. (1986). Cerámicas comunes altomedievales: contribución al estudio del tránsito de la antigüedad al mundo paleoislámico en las comarcas meridionales del País Valenciano. Lucentum, V, 147-167. DOI: https://doi. org/10.14198/LVCENTVM1986.5.09

Gutiérrez Lloret, S. (1996). La cora de Tudmīr de la Antigüedad Tardía al mundo islámico. Poblamiento y cultura material. Madrid: Casa de Velázquez.

Gutiérrez Lloret, S. (2015). Casa y Casas: reflexiones arqueológicas sobre la lectura social del espacio doméstico medieval. En M. ${ }^{a}$ E. Díez Jorge y J. Navarro Palazón (Eds.). La casa medieval en la península ibérica (pp. 17-48). Madrid: Sílex. Recuperado de: http://hdl.handle.net/10045/74747

Gutiérrez Soler, L. M. ${ }^{\mathrm{a}}$, Rueda Galán, C., Beatriz Luna, M. y Díaz García, M. ${ }^{a}$ J. (2005). Las cuevas de Giribaile: nuevas aportaciones para el estudio del poblamiento eremítico en 
Andalucía Oriental. Arqueología y Territorio Medieval, 12, 7-37. DOI: https://doi.org/10.17561/aytm.v12i1.1717

Hernández Carrasco, C. V. (1975-76). El árabe en la toponimia murciana. Anales de la Universidad de Murcia. Filosofía y Letras, 34, 153-256.

Historia de los hechos de Don Rodrigo Ponce de León, Marqués de Cádiz (1893). Colección de Documentos Inéditos para la Historia de España, tomo CVI. Madrid.

Ibn 'Āsim. Ŷunnat al-rị̣ā fì l-taslīm li-mā qaddara Allāh wa-qaḍà. Vol. II. Ed. Ammán, 1989.

Ibn al-Jațīb. Al-Iḥāța fì ajbār garnāṭa. Vol. II. Ed. El Cairo, 1974.

Ibn al-Jațīb. Nufāẹat al-ŷirāb fi 'ulātat al-igtirāb. Vol. III. Ed. Casablanca, 1989.

López de Coca Castañer, J. E. (1975). La tierra de Málaga a fines del siglo $X V$. Granada: Universidad de Granada.

Marmolejo Cantos, F. (2014). Geografía castral en la comarca malagueña de Sierra de las Nieves. Revista del Centro de Estudios Históricos de Granada y su Reino, 29, 89-108.

Marmolejo Cantos, F. (2020). Arquitectura omeya en los yacimientos de Bobastro y Castillejos de Quintana (Málaga). Nuevas evidencias arqueológicas. Málaga: Asociación Arqueológica de Coín.

Marmolejo Cantos, F. y Cortés López, J. (2021). Las defensas de hiṣn Qannīt (Cañete la Real - Málaga) y la revuelta de los Banū 1-Jalī': fortalezas, cerámica y fuentes escritas. En la España Medieval, 44, 397-423. DOI: https://doi.org/10.5209/ elem. 75427

Martín Gutiérrez, E. (2003). Análisis de la toponimia y aplicación al estudio del poblamiento. El alfoz de Jerez de la Frontera durante la Baja Edad Media. Historia. Instituciones. Documentos, 30, 257-300.

Martínez Enamorado, V. (2006). Algunos topónimos andalusíes de la tierra de Antequera. Estudios sobre Patrimonio, Cultura y Ciencias Medievales, VII-VIII, 219-242.

Montagne, R. (1930). Villages et kasbas berbères. Tableau de la vie sociale des berbères sédentaires dans le sud du Maroc. Paris: Librairie Félix Alcan.
Ramos Muñoz, J. F., Espejo Herrerías, M. ${ }^{a}$ del M., Cantalejo Duarte, P. y Martín Córdoba, E. (1990). Informe sobre las prospecciones arqueológicas superficiales realizadas en el valle del Turón, término municipal de Ardales (Málaga). Anuario Arqueológico de Andalucía/1987, vol. II, 66 y ss.

Reyes Martínez, A., Jiménez Requena, D. M. y Lázaro Guill,

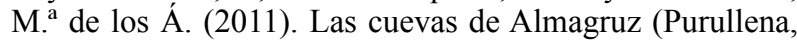
Granada). Antigüedad y cristianismo, XXVIII, 465-477.

Ribera, A. (2010). Las cuevas de Benaxuay. Un grupo de cuevas-ventana andalusíes en el río Chelva (Valencia). Cuadernos de Madinat al-Zahra, 7, 343-367.

Ribera, A. y Bolufer, J. (1994). Coves-finestra de cingle al País Valencià. Un avanç. En Actes del IV Congrés d'Arqueologia Medieval Espanyola, t. III (pp. 625-643). Alicante: Diputación Provincial.

Ribera, A. y Bolufer, J. (2008). Les covetes dels Moros. Coves-finestra de cingle al País Valencià. En M. González Simancas (Ed.). Les Casetes dels Moros del Alto Clariano. Reedició de l'original de 1918 (pp. 9-51). Collecció Estudis Locals. Bocairent: Ajuntament de Bocairent.

Terés Sádaba, E. (1986). Materiales para el estudio de la toponimia hispanoárabe. Nomina Fluvial, vol. I. Madrid: CSIC.

Terés Sádaba, E. (1990). Antroponimia hispanoárabe (Reflejada por las fuentes latino-romances). Anaquel de estudios árabes, 1, 129-186.

Taylor, R., Pérez Aguilar, L. G. y García Rivero, D. (2018). La secuencia arqueológica andalusí (siglos XI-XII) de la Cueva de La Dehesilla (Sierra de Cádiz, España). Arqueología y Territorio Medieval, 25, 107-143. DOI: https://doi. org/10.17561/aytm.v25.4

Tramoyers Blasco, L. (1899). Las cuevas de Bocairente (nota arqueológica). Revista de Archivos, Bibliotecas y Museos, III(3-4), 137-144.

Urbano Pérez, J. A. (1998). La villa de Monda en el siglo XVI: Apeos y primeras ordenanzas. Coín: Ed. Coincidentes.

Vallvé Bermejo, J. (2004). Omar ben Hafsun, rey de Marmullas (Comares). Boletín de la Real Academia de la Historia, 201(II), 213-304. 